\title{
Awareness and Willingness to Use Pre-Exposure Prophylaxis (Prep) Amongst Men Who Have Sex with Men (MSM) in China: A Mini-Review
}

\section{Yi Ren ${ }^{1, *}$, Jing $\mathrm{Pu}^{2}$, Jeffrey $\mathrm{Liu}^{2}$}

${ }^{1}$ Glaxosmithkline Beijing, 100025

${ }^{2}$ School of Medicine Tsinghua University, Beijing, 100084

${ }^{*}$ Corresponding author: Yi Ren, Glaxosmithkline Beijing, 100025, E-mail: RenaYiRen@hotmail.com

Received Date: August 28, 2019 Accepted Date: October 14, 2019 Published Date: October 16, 2019

Citation: Yi Ren (2019) Awareness and Willingness to Use Pre-Exposure Prophylaxis (Prep) Amongst Men Who Have Sex with Men (MSM) in China: A Mini-Review. J HIV AIDS Infect Dis 5: 1-13.

\begin{abstract}
The purpose of this review is to research the awareness of and willingness to use pre-exposure prophylaxis (PrEP) to protect themselves from HIV infection amongst MSM in China. In addition, we explored the potential impact factors and evaluated the need and user preferences related to access and utilization ofPrEP in China. PUBMED, EMBASE, and CNKI were accessed to search for the relevant articles published before August 2019. The studies included in this review were conducted in 9 cities in China. The awareness of PrEPuse was from 11.2\% (Zhou et al., 2012) to 52.7\%(Peng et al., 2019). The lowest willingness to use PrEP was 19.1\% (Ding et al., 2016), the highest is 91.9\% (Wei et al., 2011) provided the drug is safe, effective and free. Assuming HIV prevention medicines are effective and safe, the willingness to use PrEP was in the range of 63\%-89.8\%. Factors associated with willingness to use PrEPinclude the factors of drug products (e.g., perceived safety, efficacy, price and dosing schedule, etc.); sociodemographic characteristics (e.g., age, education, income, sex identity and sex role, etc.); behavioral factors (e.g., drug use, condom use, STI history and sex partner, etc.), and the awareness and knowledge of HIV treatment and prevention. Results indicate that as more MSM in China are becoming aware of PrEP, the willingness to use PrEP is higher than 63\% if the medicine is safe and effective. Future research is needed to solicit effective education and intervention programs to support the access and use of PrEP.
\end{abstract}

Keywords: pre-exposure prophylaxis (PrEP); men who have sex with men (MSM); Human immunodeficiency virus (HIV); Acquired immune deficiency syndrome (AIDS); awareness; willingness.

(C)2019 The Authors. Published by the JScholar under the terms of the Creative Commons Attribution License http://creativecommons.org/licenses/ by/3.0/, which permits unrestricted use, provided the original author and source are credited. 


\section{Introduction}

In 2018, 1.7 million people became newly infected with HIV, 37.9 million people were living with HIV, the risk of acquiring HIV is22 times higher among men who have sex with men [1]. Global HIV epidemic among men who have sex with men (MSM) remained uncontrolled [2].

\section{Epidemic in China}

Human immunodeficiency virus (HIV) infection has caused a huge burden and imposed a serious public health challenge to China. The National Health and Family Planning Commission (now renamed the National Health Commission) of China recently published data regarding the national (excluding Hong Kong, Macao, and Taiwan) infectious disease epidemic situation in 2018. This report indicated that 64,170 cases of new HIV infection were reported and the incidence of HIV infection was 4.6195 per 100,000 , the number of deaths was 18,780 and the mortality was 1.352 per 100,000 [3]. A meta-analysis reported a pooled incidence of HIV incidence among Chinese MSM is $5.61 / 100$ person-years, with an increasing trend over time [4]. Unprotected anal intercourse is common and puts MSM in China at high risks of acquiring and transmitting HIV [5]. In Sichuan province, the average survival time of HIV/AIDS cases was 11.51 years during 1991- 2017 [6]. With education, HIV counseling and testing, and increasing use of highly active anti-retroviral therapy (HAART) in China, HIV infected individuals have been discovered early, the mortality of HIV/AIDS patients has been significantly reduced after treatment.

In the past ten years, the transmission of HIV infection in China has changed significantly. In 2005, HIV infection was mainly through injecting drugs, transfusion, and heterosexual intercourse. By the year 2015, heterosexual/homosexual intercourse and illicit drug injection have become the main route of transmission. The proportion of homosexual in newly identified HIV subjectshas increased from $0.3 \%$ in 2005 to $27.6 \%$ in 2015 [7]. Further, a systematic review showed that HIV prevalence in men who have sex with men(MSM) increased from $1.77 \%$ (1.26-2.57) in 2000 to $5.98 \%$ (4.43-8.18) in 2010, with a national incidence of $0.98(0.70-1.25)$ per 100 person-years in 2010(8). From 2010 to 2015, HIV antibody positive rate amongst MSMat sentinel surveillance sites increased from $5.73 \%$ to $7.98 \%$ [9]. MSM had quickly become a high-risk population for HIV infection and the growing epidemic amongst MSM is one of the new challenges regarding HIV prevention/treatment in China.

\section{Pre-Exposure Prophylaxis (PrEP)}

Antiretroviral agents remain the cornerstone of HIV treatment and prevention [10]. HIV pre-exposure prophylaxis (PrEP) typically refers to the use of antiviral drugs as a strategy to prevent the acquisition of HIV amongst HIV-uninfected people [11,12]. Randomized placebo-controlled trials [13], as well as the PROUD study [14], have shown that daily oral PrEP reduces the risk of HIV infection when medications are taken as indicated. PrEP has been shown to be effective and acceptable amongst MSM in multiple clinical trials $[15,16]$. WHO recommends PrEP to be used as part of a package of prevention interventions that also include male and female condoms, voluntary medical male circumcision, prevention of mother-to-child HIV transmission (PMTCT) and harm reduction strategies such as the provision of sterile injecting equipment and opiate substitution therapy for people who inject drugs [11]. PrEP is not only highly effective within the MSM subject population at the individual level, but it is also effective on population-level, for example, intensive promotion of PrEP within the MSM population in Australia has reduced the overall incidence in this population [17]. HIV/AIDS strategy emphasizes the importance of bringing prevention to the most at-risk populations. While, PrEP may be particularly challenging among key populations such as MSM in low- and middle-income countries where healthcare infrastructure and socio-cultural contexts are extremely different from that in developed countries [18].

As of March 2018, PrEP has been approved in more than 50 countries globally [19]. Despite the effectiveness of PrEP, it has not been adopted in many countries including China. Within China, numerous activities have been initiated in order to address the growing problem of HIV infection, including condom use, voluntary HIV testing and counseling services, HIV treatment as prevention (TasP) [20]. A compartmental model for HIV suggested that without PrEP, there will be 1.1-3.0 million new infections and 0.7-2.3 million HIV-related deaths in the next two decades in China [21]. To achieve HIV elimination in the next 10, 15 and 20 years in China, the required PrEP coverage rates would be $65 \%, 32 \%$ and $19 \%$, respectively, if $100 \% \operatorname{PrEP}$ compliance [22]. It is necessary to strengthen the comprehensive intervention in MSM, including improving PrEP adherence.

One study identified moderate acceptability (57.8\%) of PrEP in MSM worldwide, showed efficacy, perception of HIV risk and experienced stigma determine its acceptance [23]. However, very few surveys exploring PrEP use amongst MSM population have been published and there are not any guidelines or medicines approved for PrEP in China. The goal of this review 
is to understand the awareness of and willingness to use PrEP amongst Chinese MSM. In addition, for those showing a willingness to use PrEP, we examined the factors involved in that decision, including the user preferences to access and utilize PrEP. The data may help to better understand the motivations and willingness to use PrEP beyond clinical trials amongst MSM.

\section{Materials and Methods}

Both PUBMED and EMBASE were used to research the relevant articles using the keywords "PrEPor pre-exposure prophylaxis", "MSM or men who have sex with men" and "China or Chinese", and searched CNKI (National Knowledge Infrastructure) to identify the relevant Chinese-language articles using the keywords "暴露前 (Bao Lu Qian) or PrEP” and “男男 (Nan Nan) or MSM" on human subjects published from 2008 to February 2018. Two reviewers (Y. R. and J. P.) independently extracted and tabulated all data. Discrepancies were resolved by discussion and agreement.

\section{Results and Discussion}

\section{Results}

\section{Summary of included studies}

This review involved a total of 98 identified publications and 27 articles were excluded due to duplication. Additional exclusions $(n=58)$ were due to a variety of reasons, including (i) review articles, (ii) not focused on the Chinese mainland, (iii) articles focussed on other outcomes or (iv) non-peer reviewed articles, (v) in-depth interview which has small sample size. Two more Chinese language articles were added additionally.

Finally, 15 publications were included in the analysis which reports data from the following cities; Shanghai, Beijing, Shenyang, Wuhan, Chengdu, Wulumuqi, Guangxi, Chongqing, and Sichuan. A flow diagram illustrating the literature search, article selection, and final included studies is shown below (Figure $1)$.

Figure 1, Study selection.

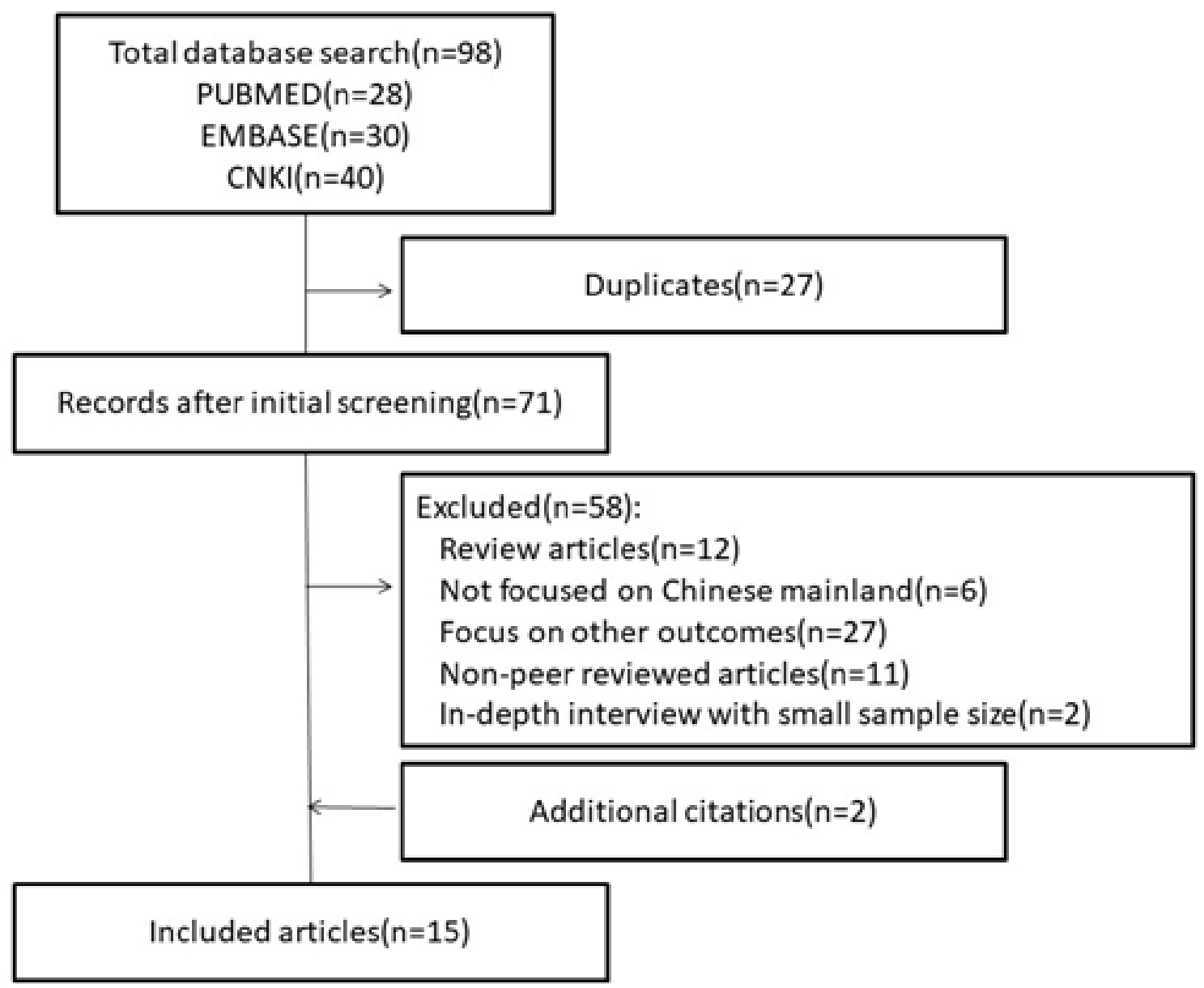

The 15 studies involved about 12,000 Chinese MSM. The MSM describe their sexual orientation as gay, bisexual or heterosexual. 13 studies only explored oral PrEP, "PrEP" in the articles regards to "oral PrEP", while 2studies explored both oral and long-acting injectable (LAI) PrEP. 
Table 1: Characteristics and findings of the included studies.

\begin{tabular}{|c|c|c|c|c|c|c|}
\hline $\begin{array}{l}\text { Author AND } \\
\text { publication } \\
\text { year }\end{array}$ & $\begin{array}{l}\text { Data collec- } \\
\text { tion period }\end{array}$ & $\begin{array}{l}\text { Country/ } \\
\text { City }\end{array}$ & $\begin{array}{l}\text { Sample } \\
\text { size }\end{array}$ & $\begin{array}{l}\text { Participants' characteristics on } \\
\text { age }\end{array}$ & $\begin{array}{l}\text { Awareness } \\
\text { to } \operatorname{PrEP}\end{array}$ & $\begin{array}{l}\text { Willingness to } \\
\text { use PrEP (com- } \\
\text { bined different } \\
\text { form) }\end{array}$ \\
\hline $\begin{array}{l}\text { Han et al. } \\
(24), 2019\end{array}$ & $\begin{array}{l}19^{\text {th }} \text { Jan to } \\
6^{\text {th }} \mathrm{Feb} 2017\end{array}$ & China & 4581MSM & $\begin{array}{l}\text { Age } \geq 15 \text { years. } \\
\text { The majority of participants } \\
\text { were } 18 \text { to } 25 \text { years old }(54.6 \%) \text {. }\end{array}$ & $22.4 \%$ & $75.6 \%$ \\
\hline $\begin{array}{l}\text { Peng et al. } \\
(25), 2019\end{array}$ & $\begin{array}{l}\text { Nov } 2018 \text { to } \\
\text { March } 2019\end{array}$ & Chengdu & $524 \mathrm{MSM}$ & $\begin{array}{l}\text { Mean age }=27.65( \pm 8.1) . \\
50.9 \% \text { of the participants were } \\
\text { younger than } 25 \text { years old. }\end{array}$ & $52.7 \%$ & $84.9 \%$ \\
\hline $\begin{array}{l}\text { Zheng et al. } \\
(26), 2019\end{array}$ & Not reported & Guangzhou & $541 \mathrm{MSM}$ & $\begin{array}{l}50.8 \% \text { of participants were } \\
\text { younger than } 30 \text { years of age. }\end{array}$ & $\begin{array}{l}\text { Not re- } \\
\text { ported }\end{array}$ & $\begin{array}{l}64.7 \% \text { willing } \\
\text { to use PrEP or } \\
\text { uncertain about } \\
\text { uptake }\end{array}$ \\
\hline $\begin{array}{l}\text { Wang et } \\
\text { al.(27), } 2018\end{array}$ & $\begin{array}{l}\text { May } 2015 \text { to } \\
\text { Dec } 2015\end{array}$ & $\begin{array}{l}\text { Wuhan, } \\
\text { Shanghai }\end{array}$ & 487MSM & $\begin{array}{l}\text { Mean age }=27.68 \text { ( } \pm 7.15 \text { years). } \\
\text { Age range }=18-61 \text { years. }\end{array}$ & $\begin{array}{l}\text { Not re- } \\
\text { ported }\end{array}$ & $71.3 \%$ \\
\hline $\begin{array}{l}\text { Meyers et al. } \\
(28), 2018\end{array}$ & $\begin{array}{l}\text { Oct } 2013 \text { to } \\
\text { Jan } 2014\end{array}$ & $\begin{array}{l}\text { Beijing, } \\
\text { Shenyang }\end{array}$ & 200MSM & $\begin{array}{l}\text { Mean age }=31.6 \text { years. } \\
\text { Age range }=18-56 \text { years }\end{array}$ & $33 \%$ & $78.5 \%$ \\
\hline $\begin{array}{l}\text { Xie et al. } \\
(29), 2017\end{array}$ & $\begin{array}{l}\text { Aug } 2015 \text { to } \\
\text { Nov } 2015\end{array}$ & Wuhan & 301MSM & Age range $=18-61$ years. & $17.28 \%$ & $77.42 \%$ \\
\hline $\begin{array}{l}\text { Mao et al. } \\
(30), 2017\end{array}$ & $\begin{array}{l}\text { Nov } 2015 \text { to } \\
\text { May } 2016\end{array}$ & Shenyang & 292MSM & Mean age $=29$ years & $34.2 \%$ & $61 \%$ \\
\hline $\begin{array}{l}\text { Wei et al. } \\
(31), 2016\end{array}$ & $\begin{array}{l}\text { Sep } 2014 \text { to } \\
\text { Feb } 2016\end{array}$ & Guangxi & 295MSM. & $\begin{array}{l}\text { Mean age }=23 \text { years. } \\
\text { Age range }=18-26 \text { years. }\end{array}$ & $19.7 \%$ & $89.8 \%$ \\
\hline $\begin{array}{l}\text { Ding et al. } \\
(32), 2016\end{array}$ & $\begin{array}{l}\text { Oct } 2012 \text { to } \\
\text { Dec } 2013\end{array}$ & Shanghai & 1033MSM & $\begin{array}{l}\text { Age range }=>18 \text { years } \\
76.7 \% \text { were younger than } \\
35 \text { years. }\end{array}$ & $\begin{array}{l}\text { Not re- } \\
\text { ported }\end{array}$ & $\begin{array}{l}19.1 \% \\
(197 / 1033)\end{array}$ \\
\hline $\begin{array}{l}\text { Xue et al. } \\
(33), 2015\end{array}$ & $\begin{array}{l}\text { Nov } 2013 \text { to } \\
\text { Dec } 2013\end{array}$ & China & $760 \mathrm{MSM}$ & Age range $=18-60$ years & $\begin{array}{l}\text { Not re- } \\
\text { ported }\end{array}$ & $32.1 \%$ \\
\hline $\begin{array}{l}\text { Zhang et al. } \\
(34), 2015\end{array}$ & Not reported & Wulumuqi & 379MSM & Age range $=18-68$ years. & $\begin{array}{l}\text { Not re- } \\
\text { ported. }\end{array}$ & $68.3 \%$ \\
\hline $\begin{array}{l}\text { Zhang et al. } \\
(8), 2013\end{array}$ & $\begin{array}{l}\text { July } 2009 \text { to } \\
\text { April } 2010\end{array}$ & $\begin{array}{l}\text { Chongqing, } \\
\text { Guangxi } \\
\text { and Sichuan }\end{array}$ & $1402 \mathrm{MSM}$ & $\begin{array}{l}\text { Age range }=18-74 \text { years, } 18-24 \\
\text { years comprised } 41.5 \% \text { of the } \\
\text { sample. }\end{array}$ & $22 \%$ & $\begin{array}{l}63.6 \% \text { absolute- } \\
\text { ly and } 16.8 \% \\
\text { somewhat will- } \\
\text { ing to use PrEP }\end{array}$ \\
\hline $\begin{array}{l}\text { Zhou et al. } \\
(35), 2012\end{array}$ & $\begin{array}{l}\text { Aug } 2009 \text { to } \\
\text { Jan } 2010\end{array}$ & Beijing & $152 \mathrm{MSM}$ & Age range $=18-61$ years. & $11.2 \%$ & $\begin{array}{l}67.8 \% \text { were } \\
\text { 'definitely' or } \\
\text { 'probably' will- } \\
\text { ing to take PrEP }\end{array}$ \\
\hline $\begin{array}{l}\text { Jackson et al. } \\
\text { (36), } 2012\end{array}$ & $\begin{array}{l}\text { Dec } 2009 \text { to } \\
\text { Feb } 2010\end{array}$ & $\begin{array}{l}\text { Chongqing, } \\
\text { Guangxi } \\
\text { and Sichuan }\end{array}$ & $570 \mathrm{MSM}$ & $\begin{array}{l}\text { Mean age }=27.6 \text { years. } \\
\text { Age range }=18-62 \text { years }\end{array}$ & $\begin{array}{l}\text { Not re- } \\
\text { ported. }\end{array}$ & $\begin{array}{l}63 \% \text { had a high } \\
\text { willingness to } \\
\text { use PrEP }\end{array}$ \\
\hline $\begin{array}{l}\text { Wei et al. } \\
(37), 2011\end{array}$ & Not mention & Guangxi & 650MSM. & Mean age $=28$ years & $19.7 \%$ & $91.9 \%$ \\
\hline
\end{tabular}


Awareness and willingness of PrEPamongst MSM in

\section{China}

Awareness: Amongst the 15 publications, 9reported the results on awareness of PrEP. These studies gathered information on awareness by asking participants whether they were aware of or have had heard of PrEP. Overall awareness of PrEP was low, ranging from 11.2\% [35] in Beijing to 52.7\% [25] in Chengdu. Other cities showed similar levels of PrEP awareness such as $17.28 \%$ [29] in Wuhan,19.7\% [37] in Guangxi, 19.7\% [31] in Guangxi's university students, 22\% [38] in western China (Chongqing, Guangxi, and Sichuan), 22.4\% [24] in China online survey, 33\% [28] in Beijing/ Shenyang and 34.2\% [30] in Shenyang. In general, there doesn't appear to be a significant difference in awareness by regions.

\section{Willingness}

All the involved publications reported the willingness of PrEP use. Approximately half of the studies assessed by simply asking binary measures, while six studies rated by five-level scales and one study rated by four-level scales. The question within the studies with five-level scale was "Assuming HIV prevention medications are safe and effective, how willing are you to use them to prevent HIV?". The response options were "very unwilling, somewhat unwilling, neither willing nor unwilling(uncertain), somewhat willing (probably willing) and very willing (definitely willing)". In addition, one study evaluated willingness by four-level scales (very unwilling, unwilling, willing and very willing). Those who "somewhat (probably)" and "very (definitely)" willing on the five-level scale were grouped "willing" on a four-level scale for analysis purpose.

Amongst the 15 studies, the lowest willingness to use PrEPwas 19.1\% [32]. The highest is $91.9 \%$ with prerequisites of the drug being safe, effective and free [37]. If the HIV prevention medicines are effective and safe, the willingness to use PrEP was in the range of 63\%-89.8\%, including 63\% [36] and $80.4 \%$ [38] in western China (Chongqing, Guangxi, Sichuan), 64.7\% [26] in Guangzhou, 67.8\% [35] in Beijing, 68.3\% [34] in Wulumuqi, 77.4\% [29] in Wuhan and 89.8\% [31] in Guangxi university students respectively 71.3\% [27] MSM in Wuhan and Shanghai would be willing to use PrEP if it were made available for use in China. In the Meyers et al. study [28], 54\% (108/200) of the surveyed MSM would be willing to use oral PrEP, 76\% $(152 / 200)$ to use LAI PrEP and the combined interest in using oral and LAIPrEP was 78.5\% (157/200) in Beijing and Shenyang. In the Peng et al. study [25], willingness to use oral PrEP, LAI PrEP is $60.1 \%$ and $60.8 \%$ respectively. In general, the willingness to use PrEP is greater than $63 \%$ if the medicine is safe and effective. In contrast, an on-line study that recruited subjects throughout China [33] showed a lower willingness to use PrEP

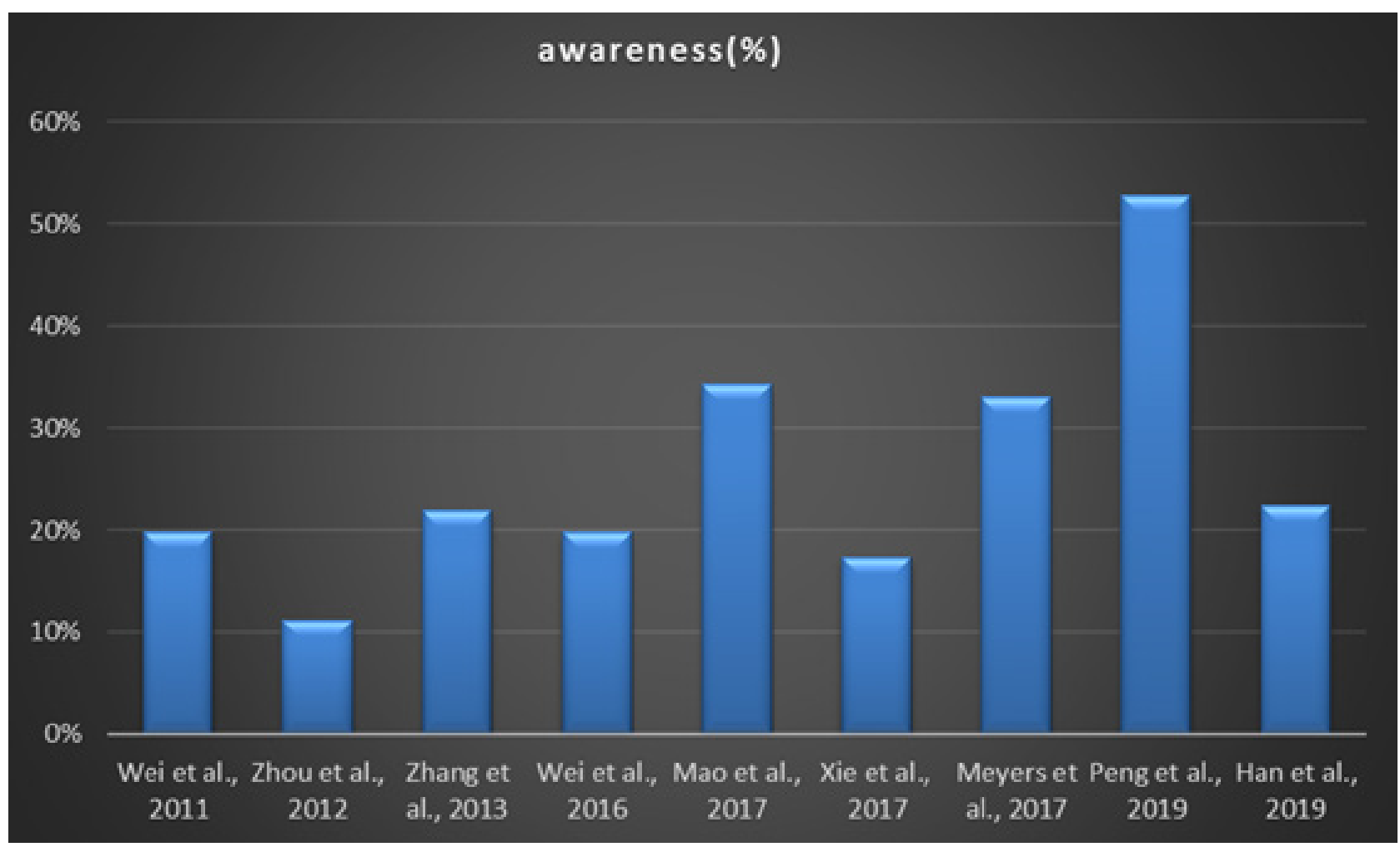

Figure 2, Awareness to use PrEPamongst MSM in China. Data were from 9 publications. 
(32.1\%). Moreover, combining the "daily" use and "on-demand" use of PrEP, the willingness to use was $61 \%$ in Shenyang [30]. In general, there does not appear to be a significant difference in willingness to use PrEP by regions or years.

\section{Impact factors on the willingness of using PrEP}

Based on included studies, I summarized 4 kinds of of factors which are potentially associated with willingness to use
PrEPamong MSM (Table.2). Included studies were variety in regions, years, enrolled population, the documented impact factors were lack of standard wordings, showed different meanings in different studies, they may bring big bias when doing analysis. These factors may play an important role in the prevention of HIV among MSM, we list the information here without analysis to provide references for future study.

Figure 3. Willingness to use PrEPamongst MSM in China. Data were from 15 publications.

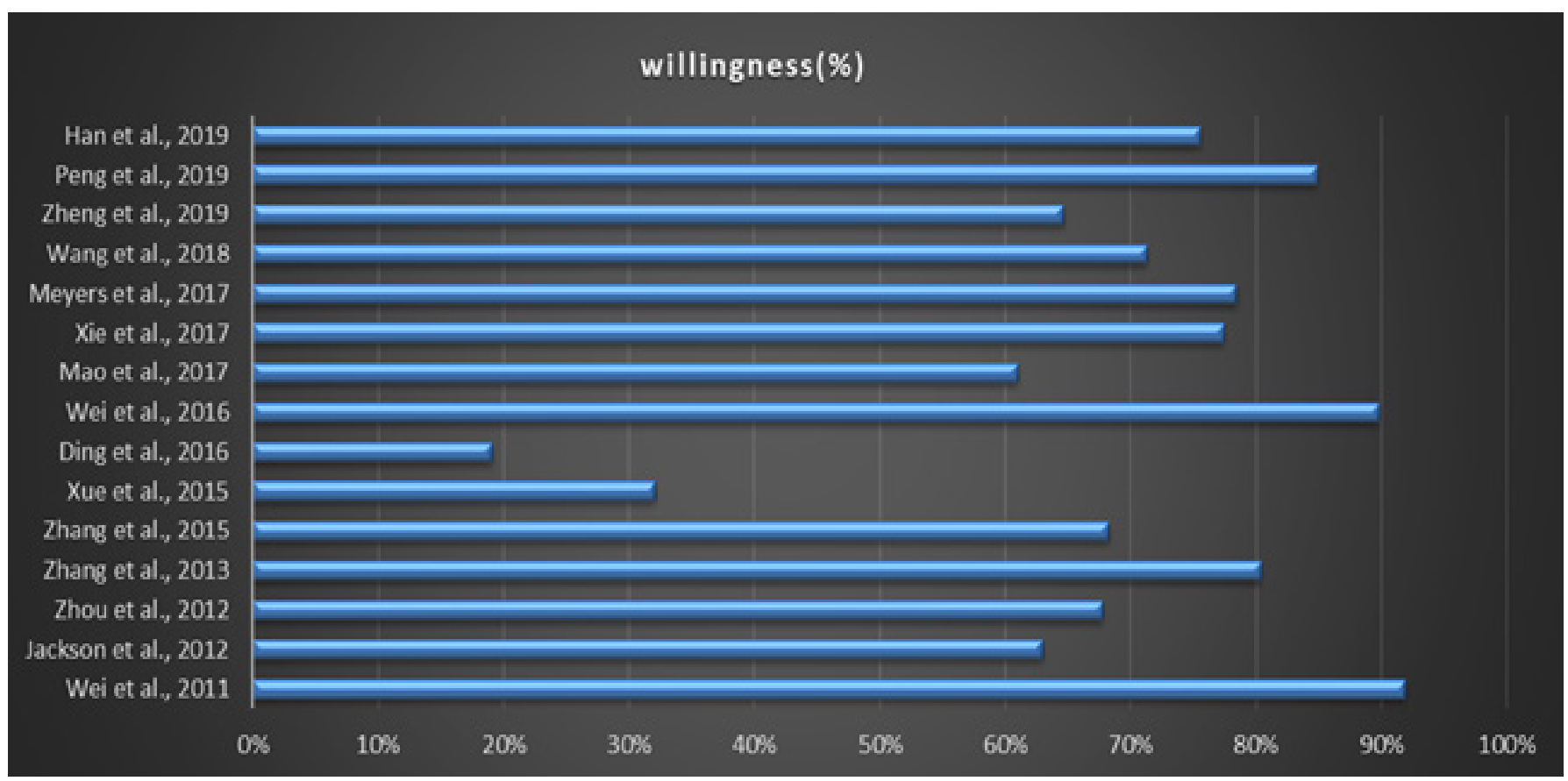

Table2: Factors affecting willingness to use HIV pre-exposure prophylaxis (PrEP) amongst men who have sex with men(MSM) in China.

\begin{tabular}{|c|c|c|c|}
\hline & Associated factors & $\begin{array}{l}\text { Source studies which analyzed } \\
\text { the factors }\end{array}$ & $\begin{array}{l}\text { Source studies which showed the factors } \\
\text { affecting willingness to use PrEP* }\end{array}$ \\
\hline \multirow{4}{*}{ Product-level factors } & Perceived safety & $(24,30,31,35)$ & $(24,30,35)$ \\
\hline & Efficacy & $(24,30,31,35)$ & $(31)$ \\
\hline & Price & $(31,35)$ & - \\
\hline & Dosing schedule & $(24,30,31)$ & $(30,31)$ \\
\hline \multirow{5}{*}{$\begin{array}{l}\text { Sociodemographic } \\
\text { factors }\end{array}$} & Age & $(24,25,28-33,35,36,38)$ & $(24,32)$ \\
\hline & Education & $(24,25,28-30,32-36,38)$ & $(28,36,38)$ \\
\hline & Income & $(24,25,29,30,33,35,36,38)$ & $(33,38)$ \\
\hline & Sex identity & $(24,25,28-33,35,38)$ & (29) \\
\hline & Sex role & $(25,28,30,31,33-35,38)$ & $(34)$ \\
\hline \multirow{2}{*}{$\begin{array}{l}\text { Awareness and } \\
\text { knowledge }\end{array}$} & Awareness of PrEP & $(24,25,28,30,31,35,38)$ & $(24,30,38)$ \\
\hline & HIV/AIDS knowledge & $(25,32,35,38)$ & $(25,38)$ \\
\hline \multirow{5}{*}{ Behavioral factors } & Drug use & $(28,30,32,38)$ & - \\
\hline & Condom use & $(24,25,27,28,30-32,34-37)$ & $(24,25,27,31,32,34-36)$ \\
\hline & STI history ${ }^{\star *}$ & $(25,28,30,34-36,38)$ & $(30,34,38)$ \\
\hline & Multiple sex partner & $(25,28,30-32,38)$ & $(25,30,32)$ \\
\hline & Stable sex partner & $(28-30,36-38)$ & $(30)$ \\
\hline
\end{tabular}

* The associations of willingness to use PrEP with impact factors were shown in the multivariate model, $\mathrm{p}<0.05$.

** STI means sexually transmitted infection 
PrEP drug-level factors(eg.perceives safety, efficacy, price and dosing schedule)

Amongst the 15 publications, 14 mentioned safety or side effect,13 mentioned efficacy.72.9\% [27] and 31.8\% [26] participants worried about side effects as the reason for not willing to use PrEP.3 studies analyzed safety or side effect as an influencing factor. One study in Beijing [35] showed those who were aware of the potential side effects of ARV drugs ( $O R=0.30$, 95\% CI: $0.14-0.67)$ were less likely to initiate prep. Those who had no worries about side effects were more probably use PrEP ( $\mathrm{aOR}=1.3,95 \% \mathrm{CI}: 1.1-1.5)$. More specifically, $44.7 \%$ of MSM participants expressed worry that PrEP would disrupted their diet and sleep. Similarly, another study in Shenyang [30] showed that in contrast to efficacy, MSM who were concerned about side effects were less likely to use PrEP.

Only one study [31] showed by multivariate logistic regression analysis that those who suspected drug efficacy $(\mathrm{OR}=0.010$, 95\%CI: 0.001-0.112) were less likely to use PrEP. Mao et al. [30] showed that compared with "on-demand" use, less MSM prefers to choose "daily" use $\left(\chi^{2}=5.785, \mathrm{P}=0.02\right)$, and amongst MSM who prefer "daily" use, only $50.3 \%$ expressed they can adhere to take medicine every day. Another study in Guangxi [31] showed by multivariate logistic regression analysis that those who felt they could adhere to daily medicine ( $\mathrm{OR}=88.245$, 95\% CI: 10.237-760.696) were more likely to use PrEP.

\section{Sociodemographic factors (Age, Education, Income, Sex identity and Sex role)}

As essential elements of the questionnaire, sociodemographic characteristics were mentioned in most of the studies.

Age: Studies showed that those who were aged $\geq 45$ years $(\mathrm{OR}=2.18,95 \% \mathrm{CI}: 1.13-4.23)$ [32] and aged $\geq 40$ years $(\mathrm{OR}=2.0$, 95\% CI: 1.1-3.6) [24] were significantly more willing to use PrEP. Education: Low education level was a predictor for willingness to use PrEP. One study showed that people with lower education $(\mathrm{OR}=1.50,95 \% \mathrm{CI}: 1.18-1.92)$ are more willing to use PrEP than people with college or higher education [38]. The other study showed that who attend post-secondary education $(\mathrm{OR}=0.72$, 95\% CI: 0.55-0.94) are less will to use PrEP than lower education [36]. In general, high willingness to use HIV PrEP was related to lower education. Also, one publication [28] showed by the multivariate model that those with higher education $(\mathrm{aOR}=0.5,95 \%$ CI: 0.2-1.0) had lower odds of being interested in LAI-PrEP only, compared with any type of PrEP.

Income: Seven studies examined the association between willingness to use PrEP and socioeconomic status/income. Xue et

JScholar Publishers al. showed that MSM who have an annual income of less than 60,000 yuan $(\mathrm{OR}=0.64,95 \% \mathrm{CI}: 0.45-0.92)$ are less likely to use PrEP [33]. And another study [38] shows that subjects with moderate-income (1000-3000yuan per month) (OR=1.31, 95\% CI: 1.02-1.67) compared with the lowest income ( $<1000 y u a n$ per month) are more willing to use PrEP.This seems to be in direct contrast to the education level data.

Sex identity and Sex role: One study [29] showed that bisexuals $(\mathrm{OR}=0.22, \mathrm{p}<0.05)$ are less likely to use PrEP than homosexuals amongst MSM who have regular homosexual partners. Whereas MSM who were "not sure" about their sexual identity were less likely to be a willingness to use PrEP (aor=0.6, 95\% CI: 0.4-0.9). Additionally, compared with receptive sex, MSM who prefer insertive sex (OR=0.34, 95\% CI: 0.19-0.60) are less likely to use PrEP [34].

\section{Awareness and Knowledge (Awareness of PrEP, HIV/AIDS knowledge)}

Awareness of PrEP: In most studies, initial awareness of PrEP was low, after the introduction of the concept, most of MSM express willingness to use it. Six studies mentioned awareness as a potential factor to a willingness to use PrEP amongst seven studies which reported awareness. After analysis, only Zhang et al. [38] and Mao et al.[30] showed that having previously heard of $\operatorname{PrEP}(\mathrm{OR}=1.33$, 95\% CI: $1.01-1.75$ and $\mathrm{aOR}=1.7,95 \% \mathrm{CI}: 1.0$ 2.8 respectively) is one of the relevant factors for willingness to accept PrEP amongst MSM. MSM who had heard of PrEP were more "definitely and probably" (aOR=1.7, 95\% CI: 1.4-2.2 and $\mathrm{aOR}=1.2$, 95\% CI: 1.0-1.5) [24] willing to use PrEP compared to those who had never heard of PrEP.

HIV/AIDS Knowledge: Zhang et al.' study [38] showed that these were more knowledgeable about AIDS (OR=1.49, CI: 1.181.88) were more willing to use PrEP. Peng et al., [25] showed who possessed a higher literacy in HIV prevention $(\mathrm{aOR}=1.49,95 \%$ CI: 1.03-2.16) were more willing to use PrEP.

\section{Behavioralfactors (Drug use, Condom use, STI history, Multi- ple sex partner, Stable sex partner)}

Drug use: No publication showed that willingness to use PrEP amongst MSM is associated with drug use.

Condom use: Amongst15 publications include, 8 studies believed that inconsistent condom use is one of the predictors of willingness to use PrEP.MSM who report condom use during their last anal sex act (OR=0.68, 95\% CI: 0.47-0.97) [32], who consistently used condom in homosexual behavior in the past 6 months (OR=0.31, 95\% CI: 0.13-0.70) [35] or in sexual intercourse with regular partners $(\mathrm{aOR}=0.47$; 95\% CI: $0.23-0.95)$ [25], prefer using condom as prevention for $\operatorname{HIV}(\mathrm{aOR}=0.5,95 \%$ 
CI: 0.4-0.5) [24] and reject sex with someone who will not use a condom $(\mathrm{OR}=0.34,95 \% \mathrm{CI}$ : 0.16-0.72) [37] were significantly less willing to use PrEP. In the multivariate logistic regression model, those who use condom occasionally $(\mathrm{OR}=1.46,95 \% \mathrm{CI}$ : 1.01-2.09) [34], and those who report barriers to condom use (OR=1.11, 95\% CI: 1.06-1.17) [36] were willing to accept PrEP. In addition, compared to always using condoms, MSM who reported never using condoms with their regular sexual partners were more likely to explain their willingness to use PrEP in terms of "problems using condoms"(39.4\% versus 6.3\%, $\chi 2=22.93$, $\mathrm{p}<0.01$ ) [27].

STI history: Five studies considered STI history as a factor for willingness to use PrEP, three of them showed a significant difference. Zhang et al. [38] and Mao et al. [30] showed that having STI history (OR=1.61, 95\% CI: $1.09-2.39$ and $\mathrm{aOR}=11.8,95 \%$ CI: 1.4-99.0 respectively) was the predictor for willingness to use PrEP.Zhang et al. showed that MSM who don't have STI history $(\mathrm{OR}=0.20$, 95\% CI: 0.07-0.56) are less willing to use PrEP [34]. Multiple sex partner: In multivariate analyses, MSM who had two or more male sex partners in the past 6 months $(\mathrm{OR}=1.53$, 95\% CI: $1.07-2.17$ for 2 to 5 and $\mathrm{OR}=1.82,95 \% \mathrm{CI}: 1.05-3.17$ for $\geq 6$, respectively) were more willing to use PrEP [32]. Mao et al.s [30] and Peng et al., reported similar results:(aOR=1.8, 95\% CI:1.1-2.9) and ( $\mathrm{aOR}=3.36,95 \% \mathrm{CI}: 1.10-10.26)$ respectively.

Stable sex partner: Mao et al. [30] showed that MSM who have stable male sex partner( $\mathrm{aOR}=1.9,95 \% \mathrm{CI}$ : 1.1-3.3) are more likely to use PrEP.

\section{Discussion}

At the community-level in China, many do not know that HIV is a manageable disease, and there is a severe lack of awareness and correct knowledge of the benefits of ART [39], even among MSM living with HIV [40, 41]. Despite PrEPbeing initially low amongst MSM in China, once they become aware of PrEP, many MSM is willing to use it. Even though the willingness to use PrEP is relatively high, the actual reported use is low $(<1 \% \sim 3.1 \%)[32,38,42]$. Perception of low HIV risk, mistrust of the national PrEP program, and concerns of side effects, lack of main sexual partner's support, difficulties in adhering to the daily oral PrEP regimen, and the inconvenient schedules in securing the medicine were the major reasons for not wanting to use or quitting the use of PrEP [43]. On the other hands, the effectiveness of oral HIV preexposure prophylaxis (PrEP) strongly depends on maintaining adherence [44]. One study showed the median adherence rate of daily oral PrEPin clinical trials was $64.29 \%$, the main objective factor in non-adherence was forgetting to take the medicine [45], LAI PrEP may improve PrEP ad- herence to some extent and may further reduce the incidence of HIV. Qu, et al. [46]. explored the impact factors to the low-level PrEP self-efficacy (Self-efficacy, as the determinant of individual behavior, is also the center of individual factors that often influences the choice and continuation of individual behavior [47] in China, age and anxiety score were negatively related to PrEP self-efficacy, AIDS-related knowledge and PrEP-related motivation were activities related to PrEP self-efficacy. One more potential reason may be a lack of community's attention or availability of approved medicine for PrEP in China. The strategy to improve PrEPactual use and adherence requires further study, such as a more robust HIV prevention care network in China may help potential uninfected subjects to understand the importance of, and how to get and use PrEP. Data from New York City indicates that delivering provider training, raising awareness and ensuring Medicaid (insurance) coverage, resulting in the number of Medicaid beneficiaries increasing from 259 in 2013 to 1330 in 2015 [48].

One study [27] showed that the top 2 reasons for willingness to use PrEP are "efficacy to sexual health" and "problems using condoms" and the top 3 reasons for unwillingness to use PrEP are "concern about side effects, long dose schedule", "confidence in protecting themselves" and "cost and atigma". Our findings suggested that several factors could potentially prevent or facilitate participants' willingness to use PrEP.Price, safe and efficacious medicine and ease of use are common concerns amongst the MSM population. If HIV prevention medicines are effective and safe, 63\%-89.8\% MSM are willing to use PrEP. Further, if reimbursement and insurance can cover the medicine for PrEP, make the price more affordable, PrEP utilization may increase. One study suggested that to achieve cost-effectiveness and realize the public health good of preventing HIV infections among MSM, current Truvada PrEP regimen in China would need to be reduced by half [21].

MSM that is age $\geq 45$ years have lower education, in a moderate-income bracket, participate in receptive anal sex, and who have more awareness of PrEP and knowledgeable about HIV/AIDSmayhave a greater willingness to use PrEP. Compared to MSM with higher education, those with lower education may be less confident to avoid risky behavior, and less knowledgable to protect themselves by traditional methods. MSM with moderate-income may be less worried about the price of PrEP compared with the lowest income. A Boston [49] study also showed that MSM with a lower education and moderate-income are more intent to use PrEP compared to those with higher education and the lowest income category. For MSM of diverse educational and demographic backgrounds, accessibility of community educa- 
tional messages should be considered [49]. Besides traditional methods, Han et al. clearly indicated that young MSM in China prefers the Internet to looking for general health information. Therefore, online educational efforts can greatly facilitate PrEP uptake among young Chinese MSM [50]. For MSM with higher education, PrEP seems to be another reliable method for them to protect themselves. PrEP would need to be integrated into existing prevention strategies, however, rather than replacing them [51]. Additionally, in order to encourage the use of PrEP, an accessible price is necessary to consider because of the cost may be a big burden for those with lower income. Negotiating with the industry and striving for subsidies from the government to make reimbursement and insurance cover medicine is a positive method to control the price. As the data reported here is limited, future studies among Chinese may be conducted more thoroughly. An interesting point in our study is the association of between MSMEs behaviors and willingness to use PrEP. While a study in Hongkong [52] showed that there were no significant associations between risky behaviors (eg.the practice of condomless sex) and PrEP acceptance which is different from mainland China.

In mainland China, recreational drug use has increased considerably amongst MSM and became a high-risk factor for HIV infection [53]. As reported by Lauby, et al. [55] and Tweed, et al. [56], recreational drug use is related to an increase in unprotected sex and HIV risk. Even though drug use did not seem to have a significant influence on the willingness to use PrEP in our review, once drug users realized they are in high HIV risk, prevention methods including PrEP may become popular among the population, further study on this factor is needed. Current literature has also identified barrier of condom use, STI history, multiple sex partner and stable sex partner as potential factors for willingness to use PrEP.It's likely that these with stronger self-perceptions of risk are more willing to explore additional protection methods, including PrEP. Condom use greatly decreases the risk of gonorrhea, chlamydia, HIV/AIDS, as well as to a lesser extent to protect against syphilis [57]. MSM who use condoms regularly regard themselves as already protected against the acquisition of HIV. Of concern, however, one study in India [58] found that availability of PrEP could reduce the use of condoms, one study showed STI is on the rise in PrEP Users [59]. Mansegh et al. [60] concluded that as PrEP becomes more available among MSM, HIV prevention programs can be enhanced in a way that reinforces condom use and helps men perceive PrEP as a supplementary biomedical intervention. For HIV and STI prevention, we should clarify if and how condoms should be used in combination with PrEP. Ongoing screening and timely treatment of STIs is both a part of broader PrEP intervention and a potential method for decreasing STI burden in the face of decreasing condom use [61]. As China begins to thinking about usingPrEP targeting MSM at high risk for HIV, it will be increasingly important to evaluate ways in which we can use PrEP programs to engage MSM in sexual health and comprehensive STI prevention programs that do not solely focus on condom use [62]. For sex partner, a study in Malaysia showed that having 2 or more male anal sex partners in the past 6 months ( $\mathrm{aOR}=1.98,95 \%$ CI: 1.29-3.05) were independently associated with greater willingness to use PrEP [63]. This is expected as other studies have shown that STI incidence increases with multiple sex partners [64]. In contrast, MSM who have stable sex partner also have a higher willingness to use PrEP in one of the six publications which analyzed this factor. One possible explanation may be that partner in such a stable same-sex relationship may have sex without a condom, but may also not be clear as to the HIV infection status of their partner. One study indicated that people were less likely to inform their main partner when they had unprotected sexual intercourses with casual partners [65]. It is reasonable for someone who has both stable and casual partners, PrEP is an attractive option for self-protection and for protection of the partner. Also, $\mathrm{Hu}$, et al. suggested that integrated delivery of sexual partners' PrEP and early ART could nearly eliminate HIV transmission and reduce costs [66].

As highlighted by the WHO guidelinec [67] there are some other potential issues among potential PrEP users, such as not taking up HIV testing regularly, not seeking medical consultation before they decide to start or discontinue using PrEP which should be monitored and prevented to ensure the effectiveness of PrEP and safety of PrEP users.

For MSM in China, we should deepen their understanding of the safety and effectiveness of PrEP and increase their confidence in PrEP, thereby improving their medication adherence [68]. Clinicians also need to be knowledgeable about PrEP as an HIV prevention tool to provide more effective sexual health services [69]. Wei, et al. [18] systematically summarized the way of successful PrEP rollout: First, health authorities should more fully engage and support community-based organizations to establish an equitable process among stakeholders. Second, broader campaigns to address lack of knowledge around PrEP medications' safety and efficacy, negative beliefs as well as HIV and sexual minority stigma. Third, government and community clinics should provide PrEP as well as MSM community partners can provide supporting counseling and monitoring. Fi- 
nally, guidelines and policies should be implemented to protect the health rights of sexual minority groups.

\section{Conclusions}

PrEP for HIV has been available since 2012 outside of China, which is a promising prevention option to prevent the acquisition of HIV for non-infected people. WHO has endorsed the use of PrEP by MSM and other populations at substantial risk of HIV [11,12]. To introduce and scale-up the usage of PrEP, it is important to learn more about user preferences and potential demand.

While willingness is not always a good indicator of future use, this helps to identify cultural values and beliefs, and concerns that need to be addressed to adequately counsel HIV high-risk individuals who would benefit from PrEP use [70].

This review contributes to knowledge around the awareness and willingness to use PrEP in China, by reporting factors that impact willingness such as product information, sociodemography, knowledge, awareness, and behavior.

In China, the awareness of PrEP is low, ranging from $11.2 \%$ to $34.2 \%$ based on these 11 studies, and one in-depth personal interview [71] even showed that no one had heard PrEPamongst the 31 subjects. In contrast, amongst those aware, the willingness to use PrEP is higher than 63\% if the medicine is presumed safe and effective. Our review also found that several factors could potentially prevent or facilitate participants' willingness to use PrEP. Drug use, unprotected (condomless) anal intercourse, STI history, and multiple sex partner are a potential predictor to a willingness to use PrEP in our study which is consistent with the target situation of PrEP. But few studies have investigated the potential use PrEP in China and the small number of studies included in our review is the biggest limitation. From the studies focused on MSM, we can further understand this population and provide appropriate advise and help for their HIV prevention. In general, future research is needed to solicit effective education and intervention programs to support access and utilization of PrEP.

\section{Acknowledgement \& declarations}

This study was supported by Tsinghua- GSK clinical and regulatory fellowship program. I appreciate Melanie Paff and Haoyu Qian for kindly advice and useful suggestions. No conflict of interest.
1. UNAIDS. Global AIDS update 20192019 [Available from: https://www.unaids.org/sites/default/files/media_asset/UNAIDS_FactSheet_en.pdf

2. Wang Z, Lau JTF, Fang Y, Ip M, Gross DL. (2018) Prevalence of actual uptake and willingness to use pre-exposure prophylaxis to prevent HIV acquisition among men who have sex with men in Hong Kong, China. PLoS ONE 13.

3. Bureau of Disease Prevention and Control NHCotPsRoC. Overview of the national legal infectious disease epidemic in 20182019 [Available from: http://www.nhc.gov.cn/jkj/s3578/20 1904/050427ff32704a5db64f4ae1f6d57c6c.shtml.

4. Zhang W, Xu JJ, Zou H, Zhang J, Wang N, Shang H (2016) HIV incidence and associated risk factors in men who have sex with men in Mainland China: an updated systematic review and meta-analysis. Sex Health.

5. Li YZ, Xu JJ, Qian HZ, You BX, Zhang J, Zhang JM, et al. (2014) High prevalence of HIV infection and unprotected anal intercourse among older men who have sex with men in China: a systematic review and meta-analysis. BMC Infect Dis 14: 531.

6. Zeng YL, Tang HL, Li JM, Wang QS, Yu H, Su L, et al. (2019) [Survival analysis of people living with HIV/AIDS in Sichuan province, 1991-2017]. Zhonghua Liu Xing Bing Xue Za Zhi 40: 309-314.

7. (2016) 6 out of every 10,000 people in China are infected with AIDS, $30 \%$ of infected people have not been found: Huanqiu Web.

8. Zhang L, Chow EP, Jing J, Zhuang X, Li X, He M, et al. (2013) HIV prevalence in China: integration of surveillance data and a systematic review. Lancet Infect Dis 13: 955-963.

9. Ge L, Li D, Li P, Guo W, Cui Y. (2017) Analysis of HIV, syphilis and HCV infection status in Chinese AIDS sentinel surveillance population from 2010 to 2015. Disease surveillance 111-117.

10. Gunthard HF, Saag MS, Benson CA, del Rio C, Eron JJ, Gallant JE, et al. (2016) Antiretroviral Drugs for Treatment and Prevention of HIV Infection in Adults: 2016 Recommendations of the International Antiviral Society-USA Panel. JAMA 316: 191210 .

11. (2012) WHO. Guidance on Pre-Exposure Oral Prophylaxis (PrEP) for Serodiscordant Couples, Men and Transgender Women Who Have Sex with Men at High Risk of HIV: Recommendations for Use in the Context of Demonstration Projects. WHO Guidelines Approved by the Guidelines Review Committee. Geneva: World Health Organization.

12. (2015) WHO. Guideline on When to Start Antiretroviral Therapy and on Pre-Exposure Prophylaxis for HIV. WHO 
Guidelines Approved by the Guidelines Review Committee. Geneva: World Health Organization.

13. Jiang J, Yang X, Ye L, Zhou B, Ning C, Huang J, et al. (2014) Pre-exposure prophylaxis for the prevention of HIV infection in high risk populations: a meta-analysis of randomized controlled trials. PLoS One 9: e87674.

14. McCormack S, Dunn DT, Desai M, Dolling DI, Gafos M, Gilson R, et al. (2016) Pre-exposure prophylaxis to prevent the acquisition of HIV-1 infection (PROUD): effectiveness results from the pilot phase of a pragmatic open-label randomised trial. Lancet 387: 53-60.

15. Hosek SG, Rudy B, Landovitz R, Kapogiannis B, Siberry G, Rutledge B, et al. (2017) An HIV Preexposure Prophylaxis Demonstration Project and Safety Study for Young MSM. J Acquir Immune Defic Syndr. 74: 21-29.

16. Harper KN (2016) Preexposure prophylaxis on-demand dramatically reduces HIV incidence in MSM. AIDS 30: N19.

17. Grulich AE, Guy R, Amin J, Jin F, Selvey C, Holden J, et al. (2018) Population-level effectiveness of rapid, targeted, highcoverage roll-out of HIV pre-exposure prophylaxis in men who have sex with men: the EPIC-NSW prospective cohort study. Lancet HIV 5: e629-e37.

18. Wei C (2018) Raymond HF. Pre-exposure prophylaxis for men who have sex with men in China: challenges for routine implementation. Journal of the International AIDS Society 21.

19. (2018) AVAC Tracking the Fast-Changing Status of PrEP Around the World.

20. (2016) Center SAPaC. Guidelines for HIV/AIDS interventions for men who have sex with men. In: Prevention CCfDCa, editor.

21. Zhang L, Peng P, Wu Y, Ma X, Soe NN, Huang X, et al. (2019) Modelling the Epidemiological Impact and Cost-Effectiveness of PrEP for HIV Transmission in MSM in China. AIDS and behavior 23: 523-533.

22. Wang K, Peng L, Gu J, Hao C, Zou H, Hao Y, et al. (2018) Impact of the 90-90-90 goal and pre-exposure prophylaxis on HIV transmission and elimination in men who have sex with men in China: A mathematical modeling study. Chinese Journal of Endemiology 39:1507-1514.

23. Peng P, Su S, Fairley CK, Chu M, Jiang S, Zhuang X, et al. (2018) A Global Estimate of the Acceptability of Pre-exposure Prophylaxis for HIV Among Men Who have Sex with Men: A Systematic Review and Meta-analysis. AIDS Behav 22: 1063 1074.

24. Han J, Bouey JZH, Wang L, Mi G, Chen Z, He Y, et al. (2019) PrEP uptake preferences among men who have sex with men in China: results from a National Internet Survey. Journal of the In- ternational AIDS Society 22.

25. Peng L, Cao W, Gu J, Hao C, Li J, Wei D, et al. (2019) Willingness to Use and Adhere to HIV Pre-Exposure Prophylaxis (PrEP) among Men Who Have Sex with Men (MSM) in China. Int J Environ Res Public Health 16.

26. Zheng ZW, Qiu JL, Gu J, Xu HF, Cheng WB, Hao C (2019)

Preexposure prophylaxis comprehension and the certainty of willingness to use preexposure prophylaxis among men who have sex with men in China. International Journal of STD and AIDS 30: 4-11.

27. Wang X, Bourne A, Liu P, Sun J, Cai T, Mburu G, et al. (2018) Understanding willingness to use oral preexposure prophylaxis for HIV prevention among men who have sex with men in China. PLoS ONE 13.

28. Meyers K, Wu Y, Qian H, Sandfort T, Huang X, Xu J, et al. (2018) Interest in Long-Acting Injectable PrEP in a Cohort of Men Who have Sex with Men in China. AIDS Behav 22: 12171227.

29. Xie PY, Wang X, Liu PL, Tan XD, Zhou W (2017) [Willingness and influencing factors of using pre-exposure prophylaxis among 301 men have sex with men in Wuhan city, 2015]. Zhonghua Yu Fang Yi Xue Za Zhi 51:1001-1006.

30. Mao X, Yu H, Hu QH, Zhang J, Chu ZX, Wang YN, et al. (2017) Acceptability of pre-exposure HIV prophylaxis clinical trial among MSM in Shenyang city. Chinese Journal of Epidemiology 38:1083-1087.

31. Wei S, Wei H, Huang X, Pan H, Tan Y, Yang G, et al. (2016) Analysis of willingness and influencing factors for usage of preexposure prophylaxis among male university students who have sex with men. Chin J Behav Med \& Brain Sci 25: 1128-1132.

32. Ding Y, Yan H, Ning Z, Cai X, Yang Y, Pan R, et al. (2016) Low willingness and actual uptake of pre-exposure prophylaxis for HIV-1 prevention among men who have sex with men in Shanghai, China. Bioscience trends 10:113-119.

33. Xue H, Liu H, Cai L (2015) Analysis of willingness and influencing factors for usage of pre-exposure prophylaxis among men who have sex with men. Zhonghua yu fang yi xue za zhi [Chinese journal of preventive medicine] 49: 973-977.

34. Zhang Z, Dilixiati Y, Jiang Y, Zhang H, Wu J, Dou Y, et al. (2015) Study on the factors influencing the acceptability of HIV prevention drugs and the choice of medication methods for men who have sex with men. Journal of Chinese Sex Science 24: $37-$ 41.

35. Zhou F, Gao L, Li S, Li D, Zhang L, Fan W, et al. (2012) Willingness to accept hiv pre-exposure prophylaxis among chinese men who have sex with men. PLoS ONE 7.

36. Jackson T, Huang A, Chen H, Gao X, Zhong X, Zhang Y 
(2012) Cognitive, psychosocial, and sociodemographic predictors of willingness to use HIV pre-exposure prophylaxis among Chinese men who have sex with men. AIDS and behavior 16:1853-1861.

37. Wei SS, Zou YF, Xu YF, Liu JJ, Nong QX, Bai Y, et al. (2011) Acceptability and influencing factors of pre-exposure prophylaxis among men who have sex with men in Guangxi. Chinese Journal of Epidemiology 32: 786-788.

38. Zhang Y, Peng B, She Y, Liang H, Peng HB, Qian HZ, et al. (2013) Attitudes toward HIV pre-exposure prophylaxis among men who have sex with men in Western China. AIDS Patient Care and STDs 27: 137-41.

39. Wei C, Yan H, Yang C, Raymond HF, Li J, Yang H, et al. (2014) Accessing HIV testing and treatment among men who have sex with men in China: a qualitative study. AIDS Care 26: 372-378. 40. Liu Y, Osborn CY, Qian HZ, Yin L, Xiao D, Ruan Y, et al. (2016) Barriers and Facilitators of Linkage to and Engagement in HIV Care Among HIV-Positive Men Who Have Sex with Men in China: A Qualitative Study. AIDS Patient Care STDS 30: 70-77. 41. Li H, Wei C, Tucker J, Kang D, Liao M, Holroyd E, et al. (2017) Barriers and facilitators of linkage to HIV care among HIV-infected young Chinese men who have sex with men: a qualitative study. BMC Health Serv Res. 17: 214.

42. Wu Y, Xie L, Meng S, Hou J, Fu R, Zheng H, et al. (2019) Mapping Potential Pre-Exposure Prophylaxis Users onto a Motivational Cascade: Identifying Targets to Prepare for Implementation in China. LGBT health. 6: 250-260.

43. Liu C, Ding Y, Ning Z, Gao M, Liu X, Wong FY, et al.(2018) Factors influencing uptake of pre-exposure prophylaxis: Some qualitative insights from an intervention study of men who have sex with men in China. Sexual Health. 15: 39-45.

44. Hoenigl M, Jain S, Moore D, Collins D, Sun X, Anderson PL, et al. (2018) Substance Use and Adherence to HIV Preexposure Prophylaxis for Men Who Have Sex with Men(1). Emerg Infect Dis 24.

45. Qu D, Zhong X, Xiao G, Dai J, Liang H, Huang A (2018) Adherence to pre-exposure prophylaxis among men who have sex with men: A prospective cohort study. International Journal of Infectious Diseases 75: 52-59.

46. Qu D, Zhong X, Lai M, Dai J, Liang H, Huang A (2019) Influencing Factors of Pre-Exposure Prophylaxis Self-Efficacy Among Men Who Have Sex With Men. Am J Mens Health. 13:1557988319847088.

47. Coffman MJ (2008) Effects of tangible social support and depression on diabetes self-efficacy. J Gerontol Nurs 34: 32-39.

48. CDC. Daily Pill Can Prevent HIV Infographics 2014 [Available from: https://www.cdc.gov/vitalsigns/hivprep/info- graphic.html.

49. Mimiaga MJ, Case P, Johnson CV, Safren SA, Mayer KH (2009) Preexposure antiretroviral prophylaxis attitudes in highrisk Boston area men who report having sex with men: limited knowledge and experience but potential for increased utilization after education. J Acquir Immune Defic Syndr 50: 77-83.

50. Han J, Bouey JZ, Wang L, Mi G, Chen Z, He Y, et al. (2019) PrEP uptake preferences among men who have sex with men in China: results from a National Internet Survey. J Int AIDS Soc 22: e25242.

51. Liu AY, Kittredge PV, Vittinghoff E, Raymond HF, Ahrens K, Matheson T, et al. (2008) Limited knowledge and use of HIV post- and pre-exposure prophylaxis among gay and bisexual men. J Acquir Immune Defic Syndr 47: 241-247.

52. Kwan TH, Wong NS, Lui GCY, Lee KCK, Lee SS (2018) Acceptability of an incentivised PrEP programme for men who have sex with men at high risk of HIV infection in Hong Kong: an implementation study. The Lancet 392:S77.

53. Zhao P, Tang S, Wang C, Zhang Y, Best J, Tangthanasup TM, et al. (2017) Recreational Drug Use among Chinese MSM and Transgender Individuals: Results from a National Online CrossSectional Study. PLoS One 12: e0170024.

54. Xu JJ, Tang WM, Zou HC, Mahapatra T, Hu QH, Fu GF, et al. (2016) High HIV incidence epidemic among men who have sex with men in china: results from a multi-site cross-sectional study. Infect Dis Poverty 5: 82.

55. Lauby J, Zhu L, Milnamow M, Batson H, Bond L, CurranGroome W, et al. (2017) Get Real: Evaluation of a CommunityLevel HIV Prevention Intervention for Young MSM Who Engage in Episodic Substance Use. AIDS Educ Prev 29: 191-204. 56. Tweed EJ, Rodgers M, Priyadarshi S, Crighton E (2018) "Taking away the chaos": a health needs assessment for people who inject drugs in public places in Glasgow, Scotland. BMC Public Health 18: 829.

57. (2007) Hatcher RAMD, Anita L. Nelson Contraceptive Technology.

58. Chakrapani V, Newman PA, Shunmugam M, Mengle S, Varghese J, Nelson R, et al. (2015) Acceptability of HIV Pre-Exposure Prophylaxis (PrEP) and Implementation Challenges Among Men Who Have Sex with Men in India: A Qualitative Investigation. AIDS Patient Care STDS 29: 569-577.

59. Barreiro P (2018) Hot News: Sexually Transmitted Infections on the Rise in PrEP Users. AIDS Rev. 20:71.

60. Mansergh G, Koblin BA, Sullivan PS (2012) Challenges for HIV pre-exposure prophylaxis among men who have sex with men in the United States. PLoS Med 9: e1001286.

61. Jenness SM, Weiss KM, Goodreau SM, Gift T, Chesson H, 
Hoover KW, et al. (2017) Incidence of Gonorrhea and Chlamydia Following Human Immunodeficiency Virus Preexposure Prophylaxis Among Men Who Have Sex With Men: A Modeling Study. Clin Infect Dis 65: 712-718.

62. Montano MA, Dombrowski JC, Dasgupta S, Golden MR, Duerr A, Manhart LE, et al. (2019) Changes in Sexual Behavior and STI Diagnoses Among MSM Initiating PrEP in a Clinic Setting. AIDS Behav. 23: 548-555.

63. Lim SH, Mburu G, Bourne A, Pang J, Wickersham JA, Wei CKT, et al. (2017) Willingness to use pre-exposure prophylaxis for HIV prevention among men who have sex with men in Malaysia: Findings from an online survey. PLoS One 12: e0182838. 64. Sicard S, Mayet A, Duron S, Richard JB, Beck F, Meynard JB, et al. (2017) Factor associated with risky sexual behaviors among the French general population. J Public Health (Oxf) 39: $523-$ 529.

65. Suzan-Monti M, Cotte L, Fressard L, Cua E, Capitant C, Meyer L, et al. (2018) Factors associated with partner notification of STIs in men who have sex with men on PrEP in France: a crosssectional substudy of the ANRS-IPERGAY trial. Sex Transm Infect 94: 490-493.

66. Hu QH, Meyers K, Xu JJ, Chu ZX, Zhang J, Ding HB, et al. (2019) Efficacy and cost-effectiveness of early antiretroviral therapy and partners' pre-exposure prophylaxis among men who have sex with men in Shenyang, China: A prospective cohort and costing study. BMC Infectious Diseases 19.

67. (2015) Guideline on When to Start Antiretroviral Therapy and on Pre-Exposure Prophylaxis for HIV. WHO Guidelines Approved by the Guidelines Review Committee. Geneva.

68. Hu Y, Zhong XN, Peng B, Zhang Y, Liang H, Dai JH, et al. (2018) Associations between perceived barriers and benefits of using HIV pre-exposure prophylaxis and medication adherence among men who have sex with men in Western China 11 Medical and Health Sciences 1117 Public Health and Health Services. BMC Infectious Diseases 18.

69. Freeborn K, Portillo CJ (2017) Does Pre-exposure prophylaxis (PrEP) for HIV prevention in men who have sex with men (MSM) change risk behavior? A systematic review. J Clin Nurs.

70. Bourne A, Cassolato M, Thuan Wei CK, Wang B, Pang J, Lim $\mathrm{SH}$, et al. (2017) Willingness to use pre-exposure prophylaxis (PrEP) for HIV prevention among men who have sex with men (MSM) in Malaysia: findings from a qualitative study. J Int AIDS Soc 20: 21899.

71. Yang X, Zhou F, Xiao D, Yu M, Li D, Zhang Z (2013) A qualitative study of the acceptability of new HIV/AIDS intervention strategies among men who have sex with men in Beijing Journal of Chronic Diseases 14: 649-653.
Submit your manuscript to a JScholar journal and benefit from:

ฯ Convenient online submission

ब Rigorous peer review

I Immediate publication on acceptance

ๆ Open access: articles freely available online

ब High visibility within the field

ब Better discount for your subsequent articles

Submit your manuscript at http://www.jscholaronline.org/submit-manuscript.php 